\title{
How safe is safe? Experiences in Dam Safety Policy
}

\author{
R. Pohl \& A. Bornschein \\ Institute of Hydraulic Engineering and Applied Hydromechanics, Technische Universität Dresden, \\ Germany
}

\begin{abstract}
Dam safety is a perpetual issue everywhere, when communities are located downstream of dams. This paper reflects experiences of the related practice and considerations in Germany. The probability of dam failure will be considered from a theoretical as well as from an empirical point of view. Information necessary in drawing up special hazard and risk maps are described and evaluated. For small dams further considerations to simplify the analysis procedure will be presented.
\end{abstract}

\section{INTRODUCTION}

During the last 100 years upstream of many cities reservoirs for water supply or hydropower have been erected. That must be included when considering the development of vulnerability and resilience of towns and cities downstream.

In Germany Owners and Operators of installations and plants with a high hazard potential are due to inform the authorities about possible accident consequences. This will help to detect hazards and to take measures if necessary. For operators of reservoirs and dams this means to inform the authorities or the public with the help of inundation maps not only about the consequences of natural floods but also about the flooding in the improbable case of a dam failure.

According to the German Dam Standard DIN 19700 and other related regulations and guidelines different dam categories due to the height $\mathrm{H}$ above the foundation, the reservoir storage $\mathrm{V}$, the importance and the hazard potential are given: Large Dams (ICOLD criterion): $\mathrm{H} \geq 15 \mathrm{~m}$ or $\mathrm{V} \geq 1$ million $\mathrm{m}^{3}$ or big hazard potential or high importance; medium dams $6 \mathrm{~m}<\mathrm{H}<15 \mathrm{~m}$, small dams $\mathrm{H} \leq 6 \mathrm{~m}$ and $\mathrm{V} \leq 100,000 \mathrm{~m}^{3}$, very small dams $\mathrm{H} \leq 4 \mathrm{~m}$ and $\mathrm{V} \leq 50,000 \mathrm{~m}^{3}$, smallest dams $\mathrm{H} \leq 1 \mathrm{~m}$ ( $\mathrm{H}$ here exceptional above terrain level) and $\mathrm{V} \leq 10,000 \mathrm{~m}^{3}$.

Although it has often been claimed that our dams are safe ,in all probabilities“ we must recognize that some medium sized German dams e.g. at Kirchheim 1977, Gissigheim 1984, Glashütte 2002 and Niedow 2010 (site in Poland but with subsequent flooding in Germany) and many small dams and levees failed during the last decades.

From these records and the appropriate statistics can be derived, that residual risks do really exist and all necessary steps must be taken to detect them and to describe their possible impact and extent.

Appropriate investigations have to be understood by the sensitive public as efforts to assess the dam safety and not as an evidence of insecurity of the dams. 


\section{RISK OF DAM FAILURE}

Much is done to keep our dams safe: high level standards and guidelines, best practice, close mashed supervision and highly qualified dam operation personnel.

The same we had also assumed to be valid for nuclear power plants that would affect much more people (even with long-term consequences) than dams in the case of failure. But the most recent incident in Fokushima, Japan, with loads beyond the design earthquake and Tsunami loads have shown us that the empirical failure probability of nuclear power stations is much higher than originally calculated and expected by the Association for Nuclear Safety. The empirical failure probability for all nuclear power plants by Kauermann \& Küchenhoff (2011) would be some 1:6600 per year [assuming the same failure probability for all plants, also if of different type; 2 accidents/30 years/440 existing nuclear power plants (during the whole 30 years)].

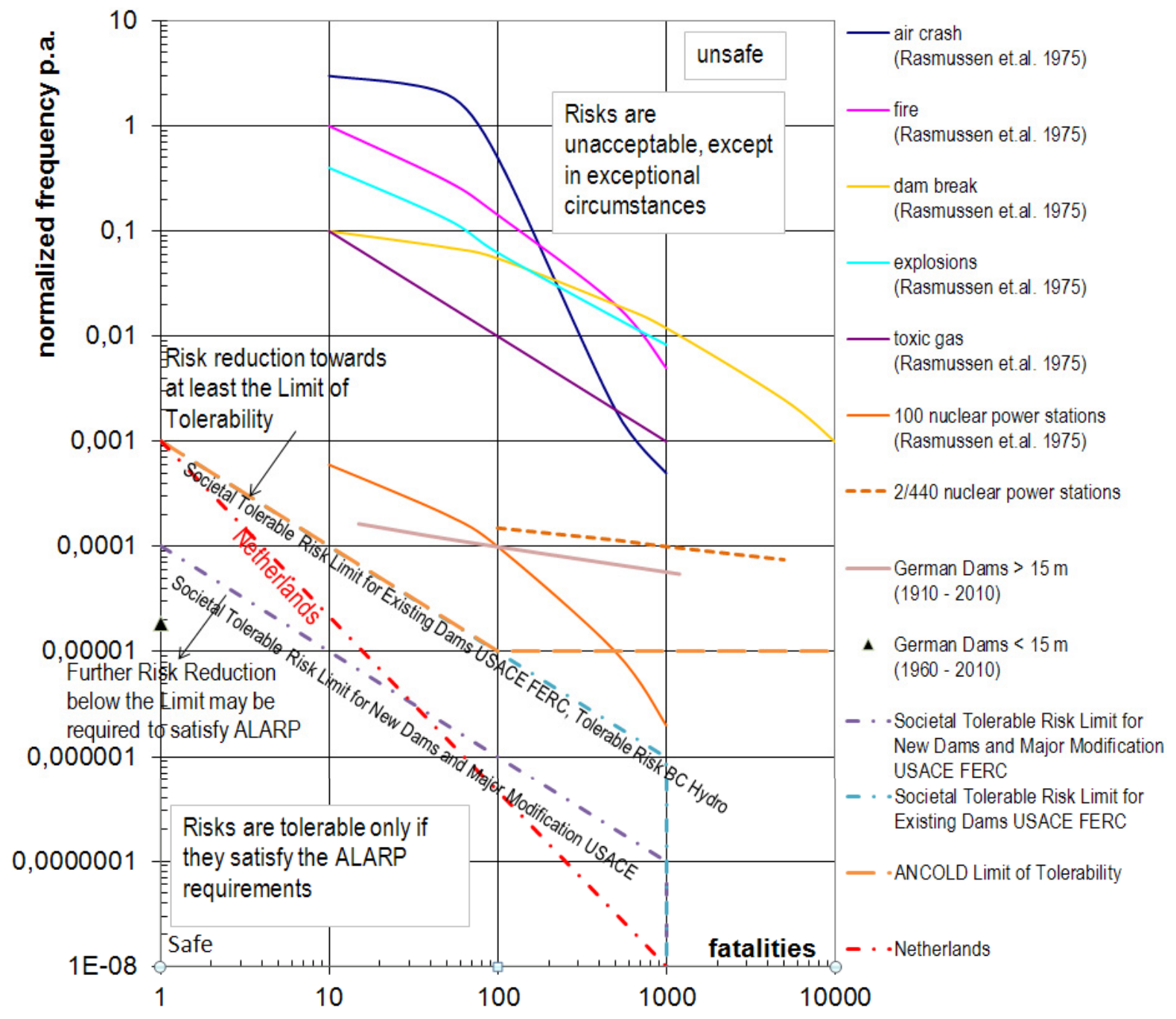

Figure 1. F-N-Diagram for several risks including tolerable limits in different countries

If the same simplified calculation is made with 4 failures of medium sized German dams during the last 65 years a failure probability of $1: 10,000$ per year $\left(1 * 10^{-4}\right)$ for a medium sized dam is yielded. Due to the lower number of fatalities related to the reported dam break events the Risk $=\mathrm{P} \cdot \mathrm{C}$ for failing of a dam is far more than one magnitude less (more secure) than of a nuclear power plant! In this first approach the num- 
ber of the not centrally registered German medium dams was estimated to be about 3 times the number of dams registered by ICOLD. For the about 300 registered large German dams (no failure during the last 40 years) the probability of about 1:14000 $\left(0.71 * 10^{-4}\right)$ has been received which is more than one magnitude less (more unsecure) than the usually calculated results. For this calculation the upper limit of the confidence interval by using the $X^{2}$-function was inserted.

One of the first reports on people at risk of large installations was the RasmussenReport (AEC 1975) with focus on nuclear power plants. Otway \& Erdman (1970) presented limiting values for the acceptance of risks: a probability of $10^{-3}$ per year with one fatality requires immediate measures of risk reducing, $10^{-4}$ demands medium-term measures, $10^{-5}$ would initiate warnings and at $10^{-6}$ individuals do not feel concerned. Further tolerable limits are given in the well-known F-N-Diagram (Fig. 1).

We can see that the results of the above dam risk approximation lie in or near the ALARP range of probabilities at about $10^{-4}$ and near the societal tolerable limit curve. This absolutely justify medium-term risk reducing and precautionary measures like drawing up and providing hazard maps. The possible consequences of a dam accident should be known to enable the responsible authorities and rescue forces to prepare appropriate preventive measures like the installation of early warning systems or the elaboration of emergency management plans. This information is needed for emergency management plans, insurance purposes or the estimation of inundation danger of important structures like chemicals factories or nuclear power plants.

\section{INUNDATION MAPPING}

Dam break surges propagate more rapidly than natural floods downstream of the failed barrage as Figure 2 shows. They can reach $5-70 \mathrm{~km} / \mathrm{h}$ and significantly exceed known flood level. A hazard estimation regarding dam break events needs information about the water depth, the flow velocity, the height of the surge as well as the concentration and quality of moving bedload and floating debris are important.

For the practical computation as a part of dam breach inundation studies several oneand two-dimensional hydro-numerical programs are available. Reliable results are yielded from those programs that keep numerical stability also with high discharge and water level gradients.


Figure 2. Left: Flood wave arrival time considering dam break events $(\mathrm{c} \approx 10 \mathrm{~km} / \mathrm{h})$ and natural floods $(\mathrm{c}$ $\approx 5 \mathrm{~km} / \mathrm{h}$ ), Right: Special hazard map with inundation area (and depth) due to a dam break wave 
When drawing up inundation maps for flooding due to hypothetical dam failure (Fig. 2) two types of maps are commonly used: a general map (scale 1:100000) with the entire flooded area and detailed maps of different cities or towns (scale of 1:10000). If the hydraulic-numerical calculation uses a one-dimensional model the maps include the following information regarding one dam failure scenario:

General map (1:100,000)

- Flooded area with water depth (marked with different colors)

- Arrival time of the flood wave, arrival time of the flood peak, peak water level above sea level and peak discharge at certain points of interest. These are often cities and towns which are presented in detailed maps too.

- Description of the assumed failure scenario.

- Diagram containing the maximum depth and discharge along the talweg for the entire river reach considered

Detailed maps $(1: 10,000)$

- Flooded area

- Water depth in the flooded area (marked with different colors)

- Location of the reference cross section (in most cases direct upstream of the first houses of a town)

- Description of the assumed failure scenario.

- Used data like digital terrain models (DTM) or software with their date of issue

- Water depth and discharge versus time at the reference cross section

- Arrival time of the flood wave, arrival time of the flood peak, peak water level above sea level and peak discharge at the reference cross section

- Diagram containing the maximum water depth and discharge along the talweg for the entire river course depicted within the detailed map

If the maps are based on two dimensional hydraulic-numerical calculation the water level or water depth are extracted at a reference point whereas the discharge is accumulated along a reference cross section. Furthermore a direct plotting of the inundated area is possible and flow velocities can be displayed in colors or with vector arrows.

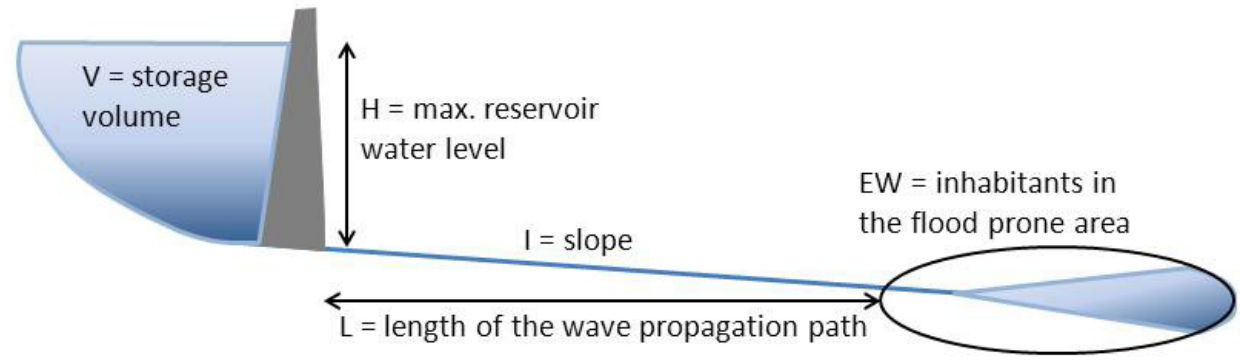

Figure 3: Sketch for risk number

In addition hazard zones can be displayed using intensity of different values (e. g. water depth $\mathrm{x}$ flow velocity or sediment layer thickness) and the occurrence probability. A flood event with high intensity that is expected frequently represents a high hazard and a high risk. Due to its very small occurrence probability a dam break often represents only a medium or small risk although it possesses a high intensity. This applies when risk is defined as a product of probability and consequences. Often the consequences are expressed by the monetary damage loss. But in addition also fatalities and destroyed parts of the cultural heritage as well as further aspects play an important role. To quantify and 
compare the hazard to the people e.g. the expression $\mathrm{V} \cdot \mathrm{H} \cdot \Sigma(\mathrm{I} \cdot \mathrm{EW} / \mathrm{L})$ can be used with the symbols explained in Figure 3.

The produced special hazard maps should be provided in well usable form: as conventional hardcopy on paper (to make it available also in the case of blackout of electricity, communication and data networks) but also in electronically stored form (GIS, internet download with possibly only authorized access).

\section{SMALL DAMS}

A frequent issue is the estimation of the residual risk for dams. Whereas for large dams the propagation of a hypothetical surge due to dam failure is usually done in most small dam cases this would exceed the available budget. This is why it has been looked for more generalized approaches.

In order to find a general approach for the estimation of the risk potential for small embankment dams there are ongoing investigations by means of a geotechnicalnumerical model (BASEMENT) at the VAW, ETH Zurich, Switzerland (VAW 2010, Volz et al. 2010). Simplified methods to estimate wave routing after to a dam break have been presented by Beffa (2001) and Bornschein (2009).
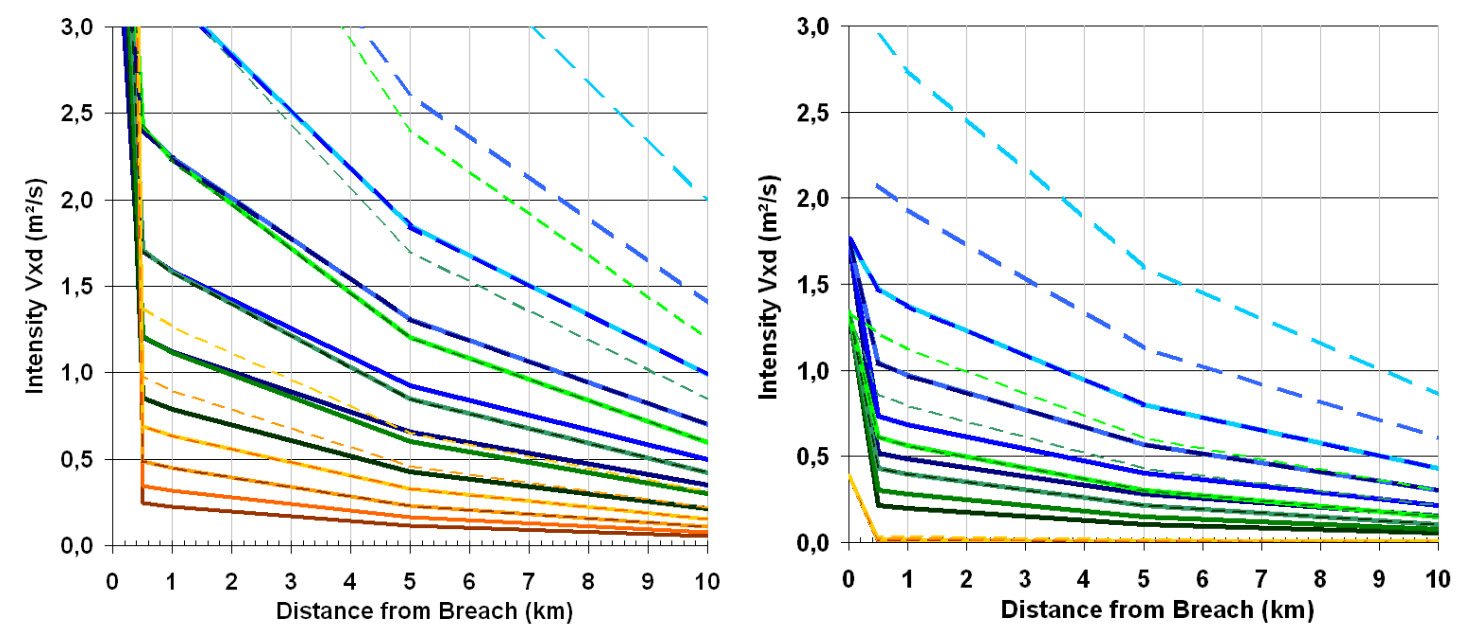

Figure 4. Generalized intensity versus surge propagation path length (typical small and very small dams, $\mathrm{H}=0.7 \ldots 4.5 \mathrm{~m}, \mathrm{~V}=10,000 \ldots 100,000 \mathrm{~m}^{3}$ ). Left: maximum breach outflow by MacDonald \& Langridge-Monopolis (1984), Right: Standard Breach by Beffa (2001), Flood routing method by Bornschein (2009)

For Figure 4 simplified hydraulic calculations assuming a Standard breach $(B=2 \cdot H$; $\mathrm{m}=1$ ) were carried out. It became visible that it is very difficult to find generalized solutions due to the manifold input data describing the dam, the breach and the valley. When using the intensity $=\mathrm{v} \cdot \mathrm{h}$ as a criterion and define $\mathrm{v} \cdot \mathrm{h}<0.5$ as harmless, $0.5<$ $\mathrm{v} \cdot \mathrm{h}<2$ as medium threat and beyond 2 as severe impact it could be derived that the expected impact and the danger for people are tolerable in the case of smallest dams everywhere, in the case of very small dams from $1 \mathrm{~km}$ and more downstream and for small dams from $10 \mathrm{~km}$ and more downstream. For other cases and more detailed information further calculations should be done. 


\section{CONCLUSIONS}

The international legislation and guidelines concerning the handling of dam break hazard maps and related emergency management plans differ considerably. In the frame of the residual risk assessment at dams the investigations should include the breach development, the outflow hydrograph, the surge wave propagation and its consequences. The result of the investigation is normally a special hazard map that should be available at least at the dam owners, operators and competent (disaster control) authorities. It can be of advantage if also the affected people are informed.

As many of the input data are uncertain quantities the hazard map displays a certain failure scenario. Different constraints and initial conditions can be taken into account by elaborating several maps. Another way for future dam break wave calculations could be the application of statistical methods that would produce water levels with a certain exceedance probability.

The legal claim for providing information concerning the possible hazard release is construed by the dam owners and operators in a different way. Especially on the question if the documents have to be ready or can be made only on demand different answers are given. Also the question if the Directive 2007/60/EC on the assessment and management of flood risks includes these ,artificial“ floods is discussed occasionally.

It seems to the authors of this paper that among the owners and operators four perspectives can be detected: The first group has published the results of the dam breach inundation studies. The second group has this information available but prefers not to publish them to avoid misunderstandings. The third group plans to cope with the problem only after request by the authorities and the fourth group is not aware of any risk related to their installations. A first estimation for large dam operators in Germany might come to the percentages of $1 \%, 30 \%, 40 \%$ and $29 \%$ where the classification regarding group 3 and 4 is difficult and may vary.

In the author's opinion despite the very low dam failure probability provisional measures should be taken as it is usual also for natural floods. These are mostly lower but with a higher probability. Especially for dams upstream of urban areas these could include the drawing up of appropriate documents with hazard maps by the dam operators.

Furthermore the disaster control authorities should consider these documents in their work and develop them towards emergency management plans. Also in this field some work is still to do.

\section{REFERENCES}

Beffa, C. 2001. Ein Parameterverfahren zur Bestimmung der flächigen Ausbreitung von Breschenabflüssen. In wasser energie luft eau energie air 93(3/4): 73-80.

Bornschein, A. 2009. A simple method to estimate inundation due to a dam break. In Bauer, E., Semprich, S. Zenz, G. (eds.). Long Term Behaviour of Dams, proc. $2^{\text {nd }}$ International Conference Graz, Austria: 751-756

IMPACT 2005. Investigation of extreme flood processes and uncertainty. Final Technical Report. www.impact-project.net

Kauermann, G. \& Küchenhoff, H. 2011. Nach Fokushima stellt sich die Frage des Risikos neu. In Frankfurter Allgemeine Zeitung, 30.3.2011: N1

MacDonald, Th.C. \& Langridge-Monopolis, J. 1984. Breaching Characteristics of Dam Failures. In Journal of Hydraulik Engineering 110(5): 567-586

Otway, H.J. \& Ermann, R.C. 1970. Reactor siting and design from a risk standpoint. In Nuclear Engineering and Design 13: 365376

AEC 1975. Reactor Safety Study - An Assessment of Accident Risk in U.S. Commercial Power Plants, WASH-1400, Atomic Energy Commission, Nuclear Regulatory Commission, Washington, USA

VAW 2011. Jahresbericht 2010 der Versuchsanstalt für Wasserbau, Hydrologie und Glaziologie, Versuchsanstalt füe Wasserbau, Hydrologie und Glaziologie, Eidgenössischen Technische Hochschule Zürich, Switzerland: 43-45

Volz, C. Rousselot, P. Vetsch, D., Müller, R., Fäh, R., Boes R. 2010. Numerical modeling of dam breaching processes due to overtopping flow. Proc. of 8th ICOLD European Club Symposium, Innsbruck, Austria 